\title{
DETERMINATION OF THE BEST WAY FOR PUTTING THE PATTERN PARTS CORRECTLY ON THE PAPER (SIMILAR TO CLOTH) (PATTERN NESTING)
}

\author{
Dr. SAMAR M. MOGLAN \\ Assistant Professor at Department of Fashion Design, College of Designs, Umm Al-Qura University, \\ Mecca, Kingdom of Saudi Arabia
}

\begin{abstract}
The garment industry is one of the industries that need to be always developed in order to keep place with the continuous global developments in fashion lines and with different fabric types in order to provide a clothing product that satisfies the taste of the consumer.

Garments are produced through a series of successive processes that differ slightly from one factory to another and each process consists of a work cycle which is a series of important elements. They begin with design, pattern making, 1pattern nesting, fabric cutting, fabric sewing in the production lines and finished with quality control and packaging so as to complete the unit of production.

It is clear that the stage of the pattern making is followed by the nesting stage, in which the different parts of the pattern are placed in a nesting way to reduce the loss of cloth. The process of nesting can be done directly on the cloth as in the garment factories or on paper as an alternative to cloth, as applied in colleges and institutes for the training of beginners and beginners on the ways of nesting in order to achieve the highest efficiency of the marker.

It has been observed in the field study that students in the fashion design course have difficulty in determining the correct way to put the parts of the pattern parts on the paper (alternative to the cloth). In this research the difficulties of putting the pattern on paper are determined and some solutions are suggested.

KEYWORDS Educational Booklet, Nesting Difficulties, Pattern Nesting \& Pattern Paper
\end{abstract}

Received: Sep 18, 2019; Accepted: Oct 08, 2019; Published: Nov 11, 2019; Paper Id.: IJTFTDDEC20192

\section{INTRODUCTION}

The garment industry is one of the most important activities, which take interest of the community; it was characterized by using a wide range of raw materials, different product types, diverse production sizes and different technology. The garment industry is defined as the processes that go through the raw materials intended for production, from fabrics to finished clothing pieces intended for consumption during the course of the various production processes, and since the beginning of this century the garment industry has witnessed many development stages, shifting from reliance on workshops and small factories limited to factories with high production, trending towards mechanism and technological methods in full production processes (Gabr 2016). Most garments are produced through a series of successive processes, described in figure 1, and we will address this in our presentation of some stages related to the subject of research (the stage of preparation of the pattern and the pattern nesting). 
The design of patterns is the first step that precedes the process of cutting and tailoring of clothes. It must give guaranteed and stable results as one of the requirements of this era, which is characterized by the speed of change and innovation in fashions and models of women's clothing.

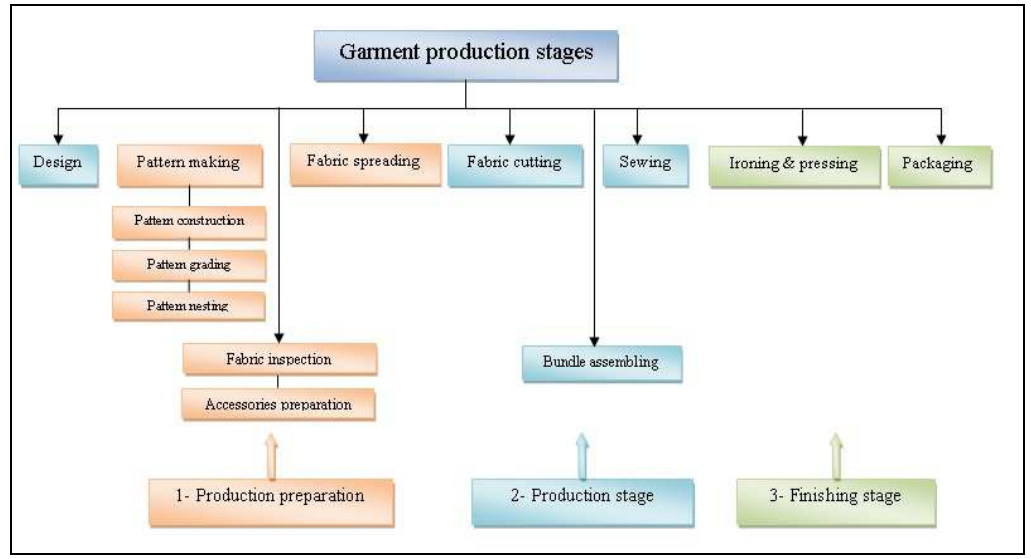

Figure 1: Stages of Garment Production.

The construction of basic flat pattern is one of the most important modern features in the implementation and manufacture of clothing. The way to the work of the various designs of the clothes pattern has become easy and easy, with the possibility of keeping the pattern in their measurements and adjusting well, and reusing them from the need for it (Bukhari 2007).

\section{How to Put Pattern on the Cloth}

A pattern is a set of pieces of paper that are executed according to certain sizes. They are then placed on the cloth in a certain way, taking into account the following:

- $\quad$ Making the pattern pieces must be completed before cutting.

- The cloth direction must be considered.

- $\quad$ The pattern should be put balanced straightly with the cloth selvage.

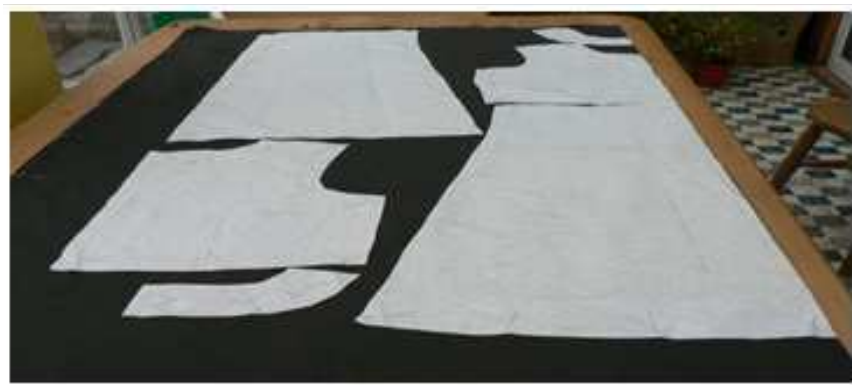

Figure 2: Correct Way to Place the Parts of the Pattern.

\section{PAPER}

The invention of paper material, as we now know, refer to the Chinese, who produced it from the first century AD and from the hollow stems of bamboo and ballet rags, or fishing nets, Hemp and Chinese grass. It is improved using bark, cannabis, hemp and cloth. 


\section{Paper Types}

- Newspaper Paper: multiple in different proportions depending on the method of manufacture.

- Magazine Paper: It is similar to newspaper paper, but it is characterized by its clear gloss. Both types of pulp extracted are chemically extracted.

- Printing Paper: Made from chemically extracted pulp, but it is added to its paste types of rags, and then the dough is chemically reprocessed. This type is highly resistant to moisture and low absorption of liquids.

- Cardboard: A common term for multiple types of paper if its thickness increases (15\%) of millimeters and its strength to hardness. The word "Cardboard" is often added to another word that is intended to be determined.

- Butter Paper: Vegetable paper, a precious paper made of patched skins from the cow and horse species, treated with sulfuric acid, unpolished, resists the depletion of fatty substances, is used in packaging butter and fat, and the weight per square meter of it is usually about 30 grams. It may be added a waxy substance that increases the nondepletion of fatty substances (Salman 2006).

Paper is used in many fields, including: writing and drawing on it, in the purposes of printing and photographing, in printing books, magazines, newspapers and for study purposes, and in the field of fashion design in the drawing of models and pattern, as well as in the development of model dissection models. Paper is used as a cloth substitute to train beginners on how to place the pattern parts on the cloth

\section{TEXTILE FABRICS}

Clothing has a great importance in our daily lives; it protects the human body to achieve a natural atmosphere surrounding it and be suitable in terms of temperature, humidity, and various weather factors, and provide us with comfort in hot weather to be light and porous. The choice of fabrics and clothes in our lives daily is not easy as it requires it to quickly trade-off as it is subject to several factors including the properties of fiber in general and therefore the characteristics of the fabrics from which the various clothed pieces are made and the need to have a functional and aesthetic element in them (El-Sherif 2008).

Before purchasing the cloth, the lengths and dimensions of the pattern pieces must be measured to determine the meters needed to implement the design (Abdeen 1986).

The width of the cloth is chosen according to the model to be implemented, but if the fabric to be executed (model) is larger than required, there are several ways to bend the cloth according to the model's need, like:

- $\quad$ Bend the cloth longitudinally from the middle.

- Bend the cloth accidentally from the middle.

- Bend the cloth longitudinally according to the desired width - not from the middle.

- Bend the cloth accidentally according to the desired width - not from the middle - because there are parts of the pattern that need all the width and there are parts that need to bend only part of it.

- $\quad$ Bend the cloth on the $45^{\circ}$ direction (Abdeen 2003). 
- When bending the cloth it must be inside to be clean and in order to facilitate the taking of marks from the back for easy execution. To adjust the fabric when bending according to the required width must measure the dimensions of selvage to the other to ensure that the fabric is straight. To cut part of the pattern, it is best to lose a weft yarn and cut to ensure that the fabric is adjusted (Abdeen 2003).

\section{Tools Used to take Marks (Sewing Limits)}

Taking marks is one of the most important steps in the implementation process, and there are several ways to take them around the parts of the pattern:

- $\quad$ Simple sewing.

- Jacket stitch (used in weaving coats, jackets and thick wool fabrics).

- Signs by roulette.

- $\quad$ Pencil and carbon marks.

- $\quad$ Mark marks (Maddy 2005).

\section{Seam Allowance}

The process of determining sewing allowance comes as the next step to put the parts of the pattern on the cloth, and is defined as: the distance between the edge of the fabric and the sewing line (the edges of the pattern), and this process is done by moving a certain distance from the edges of the pattern (figure 3 ). This distance varies according to several points:

- Depending on the purpose of the piece or product.

- Depending on the method of cleaning (finishing).

- $\quad$ Depending on the type and width of the stitches of the cleaning machine (Overlock machine).

- According to the lines of the parts of the pattern:

The lines of seam allowance are drawn around the parts of the pattern with equal dimensions for each line as follows:

- $\quad$ Pleurisy and midline $(3 \mathrm{~cm})$.

- $\quad$ Shoulder line $(2 \mathrm{~cm})$.

- $\quad$ Armpit and neck peritoneal $(1 \mathrm{~cm})$

- $\quad$ Tail-end line of the pattern $(6 \mathrm{~cm})$ (Abdeen 1986).

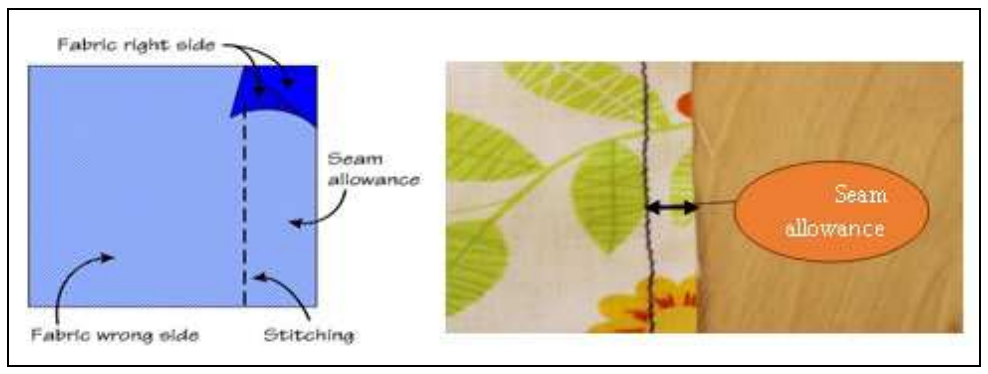

Figure 3: Seam Allowance. 


\section{Research Problem}

The problem of the research can be presented in the following questions:

- What are the difficulties faced by students of the fashion design department in putting the parts of the patterns on paper (alternative to the cloth)?

- What are the solutions and proposals to facilitate these difficulties?

\section{Research Goals}

- Developing positive solutions to the problem of students in placing the parts of the patrons on the paper (alternative to the cloth).

- Design of an educational booklet explaining how to put the parts of pattern parts on the paper

- Suggestion of special paper that makes it easier for students to put the parts of the pattern on the paper.

\section{Research Importance}

Identify the difficulties faced by students of the fashion design in placing the parts of the pattern on paper (alternative to the cloth) lead to improve their ability to create the marker with high nesting efficiency and that benefit the clothing industry from the side of reducing the cost of fabrics and money.

\section{Research Hypotheses}

- There are difficulties facing by the students of the fashion design in placing the parts of the pattern on paper (alternative to the cloth).

- Development of a paper in a special design will make it easier for students to put the parts of the pattern on paper.

- Existence of an educational booklet will make it easier for students to put the parts of the pattern on paper.

- There are no references and scientific books specialized in this field.

\section{RESEARCH TERMS}

\section{Fabrics}

It is the basic raw material for the manufacture of clothing and it consists of fabric fibers (natural, artificial) converted into textile yarns entering the fabric industry (Habib 2005).

\section{Pattern}

Lines and curves drawn on paper in artistic and geometric ways based on precise measures of a particular body and take the shape of the body by sewing and darts. It is the basis on which any design is executed (Abdeen 1986).

\section{Pattern Nesting}

Is the term for placing different parts of the pattern in an overlapping way to reduce the missing cloth (Hemdan 2007). It is also defined by Gabr (2016), how to arrange the parts of the pattern in sizes and repeated on the cloth in order to reach the highest efficiency of the nesting (The marker) and the efficiency of the marker affects the total cost of the product significantly. 


\section{Seam Allowance}

It can be defined as the distance between the edge of the fabric and the sewing line (https://en.wikipedia.org), in another definition, putting the patterns on the cloth leaving a distance from the edge of the cloth ranging from $1 / 4$ or $1 / 2$ inch (http://howtosew.com).

\section{Paper}

It is a thin flat material produced from the pulp of wood which is usually natural, so that it consists mainly of cellulose fibers; the material of those pages is used in writing, printing, wrapping house walls and kitchen bags (https://ar.wikipedia.org).

\section{RESEARCH METHODOLOG}

\section{Research Methodology}

The research approach follows the applied experimental method that is related to the field of application in general, and is interested with the application and development of the basic knowledge research.

\section{Research Sample}

The sample of the research consisted of the students of third, fifth and eighth level in the College of Designs, Fashion Design Department, where their number was 50 students, as in Table 1.

Table 1: Research Sample

\begin{tabular}{|c|c|}
\hline Study Level & Number of Students \\
\hline Level 3 & 20 \\
\hline Level 5 & 20 \\
\hline Level 8 & 10 \\
\hline Total & $\mathbf{5 0}$ \\
\hline
\end{tabular}

The researcher used more than one tool to achieve the research objectives, and included the following tools.

\section{Observing}

Observe the students in the classroom while working on putting the pattern on paper (similar to the cloth), and record the errors and difficulties faced in the application of the correct method of the situation, and write them in a form to facilitate the extraction of data from them and refer to them when needed.

\section{Interview}

The interview was conducted with the students of the third, fifth and eighth levels, and with some faculty members specialized in the field of pattern.

\section{Questionnaire}

The questionnaire consists of a set of diverse questions that are related to each other in a way that determines the objective. Therefore, the researcher subjected the information that she obtained from the interview to a classification and arrangement, and then she prepared the questionnaire items with the problem of the research and its objectives and hypotheses and formulated them in clear and specific terms and in logical order, where the researcher used the restricted picture with the specific answers (the opened closed questionnaire), and the answer is measured by the triple estimation 
balance (yes, no, sometimes) with the addition of a suggested question to any opinion or suggestion related to the research subject, so that the tested student is given the freedom to answer.

The questionnaire aims to identify the difficulties and problems faced by students in placing parts of the pattern on paper (similar to cloth), and the opinion of the research sample in the proposed solutions to solve these difficulties.

\section{Sincerity of the Questionnaire}

Sincerity refers to the ability of the questionnaire to represent what had put to measure, and that through presenting it in its initial form to the specialized professors, to identify their views in the questionnaire and its achievement to the goal that it was put for it, and the validity of the formulation of the phrases scientifically, and that has resulted some modifications in the phrases and their formulation and arrangement.

\section{Propose a Special Paper to put the Parts of the Pattern}

- Suggested paper is designed according to the offers of fabrics available in the market; easy for students to use and fold according to the appropriate width.

- Choose different colours for the paper used in printing the design.

- Adding cross lines between the paper widths in order to facilitate adjusting the orientation of the paper and put the parts of the pattern on it.

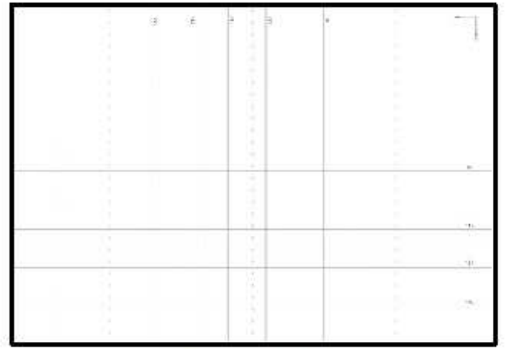

a) Suggested paper

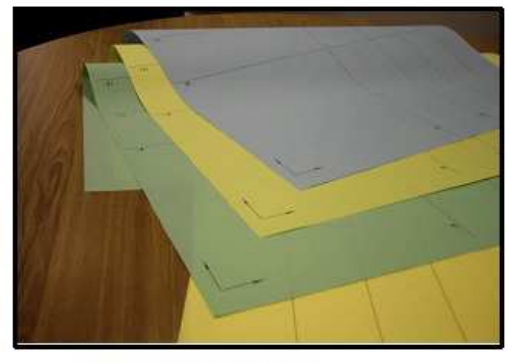

b) Different paper colours

Figure 4: Proposed Paper.

\section{Create an Educational Booklet}

Explaining the steps of putting the pattern on paper (similar to cloth)

During searching and studying it is found that there is a lack of specialized information in this area of pattern nesting, and accordingly this booklet is designed to be a reference for the correct way to put the parts of the pattern on paper (similar to the cloth). 


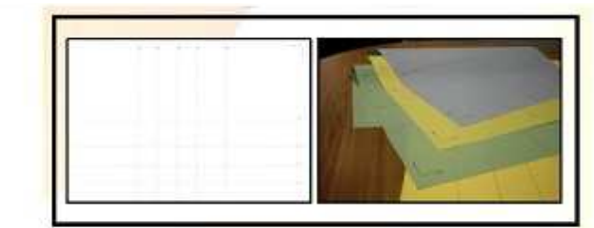

First step: Suggested paper

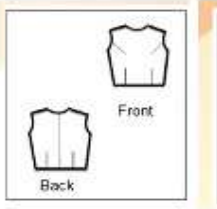

Model 1

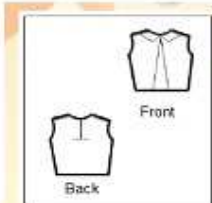

Model 2
Third step: Model selection

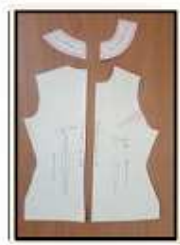

Model 1

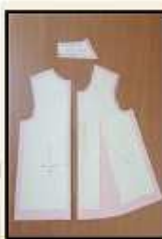

Model 2

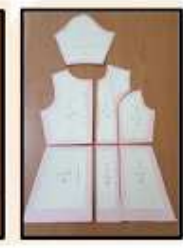

Model 3

Forth step-b: Pattern after adding details

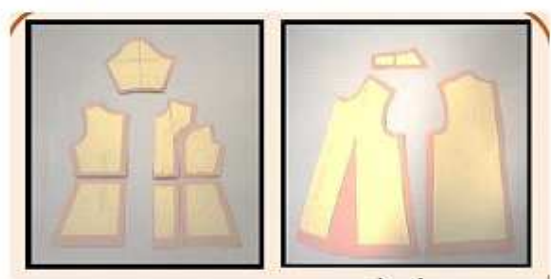

Sixth step: Seam allowance

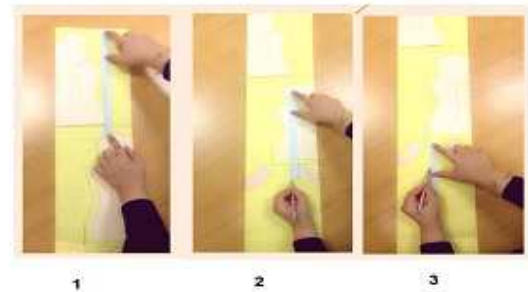

Eighth step: Determining the paper length

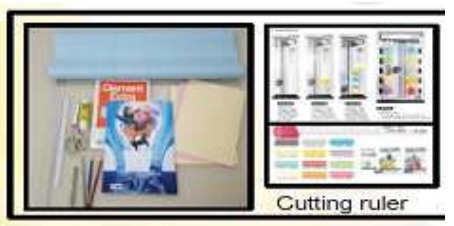

Second step: Tools

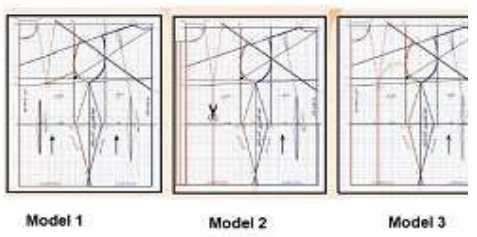

Forth step-a: Pattern drawing for the selected $r$

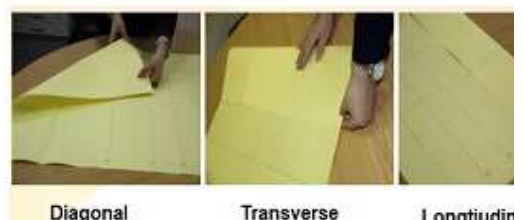

Fifth step: Paper bending

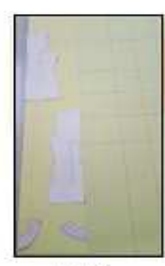

Model 1

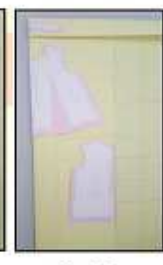

Model 2

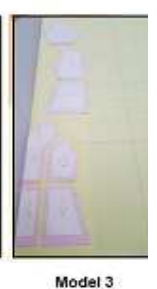

Seventh step: Pattern nesting

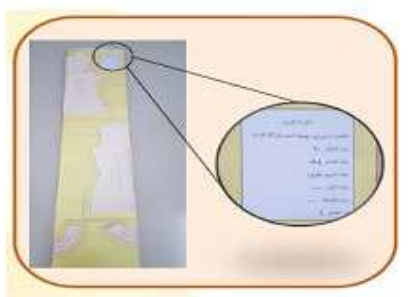

Ninth step: Pattern guide

Figure 5: Steps of Pattern making and Nesting through the Educational Booklet.

\section{RESULTS \& DISCUSSIONS}

As mentioned in the experiments, a questionnaire included 15 questions was prepared and presented to 50 students to conclude the difficulties, which they face, when putting the pattern on the paper in three cases:

- Using traditional paper and normal way to nest the pattern (Pre).

- $\quad$ Using the suggested special paper (Post 1).

- Using the suggested paper and educational booklet together (Post 1).

- The answers of the questionnaire about the difficulties, which students face during nesting the pattern, are presented in table 2 . 
Table 2: The Occurrence Percentage of Difficulties

\begin{tabular}{|c|c|c|c|}
\hline \multirow[b]{2}{*}{ Difficulties } & \multicolumn{3}{|c|}{ Difficulty Percentage [\%] } \\
\hline & Before & $\begin{array}{c}\text { After using } \\
\text { Suggested Paper }\end{array}$ & $\begin{array}{l}\text { After using Paper \& } \\
\text { Educational Booklet }\end{array}$ \\
\hline $\begin{array}{l}\text { 1- Determining the required paper } \\
\text { width for bending }\end{array}$ & 68.00 & 28.00 & 25.00 \\
\hline $\begin{array}{l}\text { 2- Determining the right way to bend } \\
\text { the paper in the warp direction }\end{array}$ & 71.33 & 41.33 & 35.33 \\
\hline $\begin{array}{l}\text { 3- Placing the pattern parts on the } \\
\text { paper }\end{array}$ & 71.33 & 29.00 & 20.00 \\
\hline $\begin{array}{l}\text { 4- Multiple parts of the suggested } \\
\text { pattern or model }\end{array}$ & 70.00 & 48.00 & 41.00 \\
\hline $\begin{array}{l}\text { 5- Different lines of the suggested } \\
\text { design when placed on paper }\end{array}$ & 74.00 & 35.67 & 29.67 \\
\hline $\begin{array}{l}\text { 6- Determining seam allowances } \\
\text { around parts of the pattern }\end{array}$ & 66.00 & 66.00 & 25.00 \\
\hline $\begin{array}{l}\text { 7- Nesting of pattern parts by } \\
\text { numbering }\end{array}$ & 54.00 & 47.33 & 27.00 \\
\hline $\begin{array}{l}\text { 8- Specify the required data in the } \\
\text { pattern guide }\end{array}$ & 65.33 & 65.00 & 22.33 \\
\hline $\begin{array}{l}\text { 9- Maintain the pattern direction in } \\
\text { the model }\end{array}$ & 72.00 & 30.00 & 24.00 \\
\hline $\begin{array}{l}\text { 10- Nesting small parts with large } \\
\text { parts }\end{array}$ & 75.00 & 33.00 & 26.00 \\
\hline $\begin{array}{l}\text { 11- Maintaining the non-overlapping } \\
\text { parts of the pattern }\end{array}$ & 65.00 & 30.00 & 29.00 \\
\hline $\begin{array}{l}\text { 12- Obtain appropriate nesting } \\
\text { efficiency }\end{array}$ & 75.00 & 25.00 & 20.00 \\
\hline 13- Use traditional paper quality & 90.00 & 10.00 & 10.00 \\
\hline 14- Lack of a guide booklet & 89.33 & 89.33 & 12.00 \\
\hline $\begin{array}{l}\text { 15- Scarcity of references and } \\
\text { scientific sources specialized in the } \\
\text { field of research in the mother } \\
\text { tongue }\end{array}$ & 85.33 & 77.33 & 55.00 \\
\hline
\end{tabular}

Through Table 2, it is clear that there are varied difficulties, which faced students during putting on the pattern on the paper. There are 4 hypothesis (represented in 15 questions) investigated and concluded in this research.

The Tests of Normality was done to determine the classification of the data, if they belong to parametric test or non-parametric test.

Table 3: Tests of Normality

\begin{tabular}{|c|c|c|c|c|c|c|}
\hline \multirow{2}{*}{} & \multicolumn{3}{|c|}{ Kolmogorov-Smirnov $^{\mathbf{a}}$} & \multicolumn{3}{|c|}{ Shapiro-Wilk } \\
\cline { 2 - 7 } & Statistic & df & Sig. & Statistic & df & Sig. \\
\hline PRE & .180 & 15 & $.200^{*}$ & .925 & 15 & .233 \\
\hline POST1-special paper & .176 & 15 & $.200^{*}$ & .924 & 15 & .225 \\
\hline POST2-special paper \& educational book & .196 & 15 & .125 & .917 & 15 & .173 \\
\hline
\end{tabular}

a. Lilliefors Significance Correction

*. This is a lower bound of the true significance.

It is clear from table 3 that the probability value $(P$-Value) for the two tests (Kolmogorov-Smirnov and ShapiroWilk) in all cases are larger than the significant level 5\%. Thus, we do not reject the null hypothesis of the model and confirm with $95 \%$ that the samples data belong to the normally distribution. This result helps the researcher to take the decision to apply the parametric tests. 
To verify the four hypotheses, the $t$ test had been applied and results were analyzed.

First statistical hypotheses were performed:

Null hypothesis: The difference between pre and post-experiment is not significant.

$\mathbf{H}_{0}: \mu_{1}=\mu_{2}$

Alternative hypothesis: The difference between pre and post-experiment is significant.

$\mathrm{H}_{1}: \boldsymbol{\mu}_{1} \neq \mu_{2}$

Table 4 shows that the value of mean of difficulties percentage in the pre-application was "72.2433", which indicates the existence of the difficulties, while in the post-application of special paper is 43.6660 and in the postapplication of special paper and the educational booklet is 26.7553 . This indicates the effectiveness of the special paper and the booklet in reducing the difficulties level for the students.

Table 4: Paired Samples Statistics

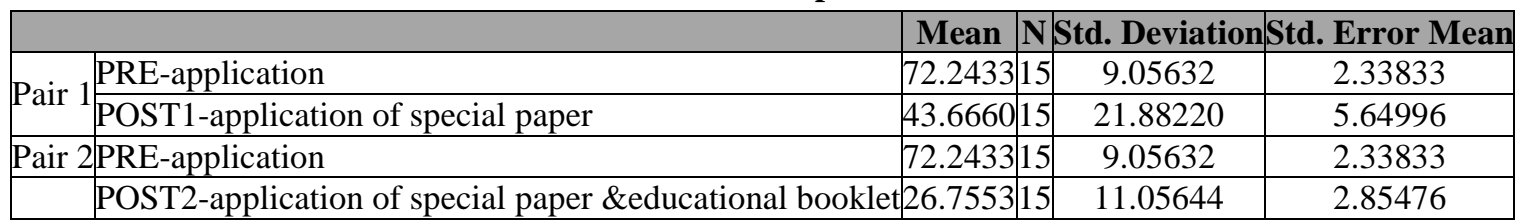

The correlation degree between pre-application and post-application of special paper is 0.029 and post-application of special paper and educational booklet is -0.304 as shown in table 5 .

Table 5: Paired Samples Correlations

\begin{tabular}{|c|l|c|c|c|}
\hline \multicolumn{2}{|c|}{} & $\mathbf{N}$ & Correlation & Sig. \\
\hline Pair 1 & $\begin{array}{l}\text { PRE- application \& POST1-application of } \\
\text { special paper }\end{array}$ & 15 & .029 & .919 \\
\hline Pair 2 & $\begin{array}{l}\text { PRE-application \& POST2-application of } \\
\text { special paper \& educational booklet }\end{array}$ & 15 & -.304 & .271 \\
\hline
\end{tabular}

Table 6 shows that by the first pair (per-application and post-application of special paper) the value of " $t$ " equals to 4.722 , and the $P$-value is 0.000 , while by the second pair (per-application and post-application of special paper and educational booklet) the value of " $t$ " equals to 10.819 , and the $P$-value is 0.000 .

Table 6: Paired Samples Test $(T$-Test)

\begin{tabular}{|c|c|c|c|c|c|c|c|c|}
\hline & \multicolumn{5}{|c|}{ Paired Differences } & \multirow{3}{*}{$\mathbf{t}$} & \multirow{3}{*}{ df } & \multirow{3}{*}{$\begin{array}{l}\text { Sig. } \\
(2- \\
\text { tailed })\end{array}$} \\
\hline & \multirow[t]{2}{*}{ Mean } & \multirow[t]{2}{*}{ Std. Deviation } & \multirow[t]{2}{*}{ Std. Error Mean } & \multicolumn{2}{|c|}{$\begin{array}{l}\text { 95\% Confidence Interval } \\
\text { of the Difference }\end{array}$} & & & \\
\hline & & & & Lower & Upper & & & \\
\hline \begin{tabular}{|c|l|} 
Pair & PRE- application \\
1 & $\begin{array}{l}\text { POST1-application of } \\
\text { special paper }\end{array}$ \\
\end{tabular} & 28.57733 & 23.44089 & 6.05241 & 15.59620 & 41.55847 & 4.722 & 14 & .000 \\
\hline \begin{tabular}{|c|l} 
& PRE-application \\
Pair & POST2-application of \\
2 & $\begin{array}{l}\text { special paper \& } \\
\text { educational booklet }\end{array}$ \\
\end{tabular} & 45.48800 & 16.28343 & 4.20436 & 36.47053 & 54.50547 & 10.819 & 14 & .000 \\
\hline
\end{tabular}

Since the $P$-value of the first pair (pre-application and post-application of special paper) and the second pair (perapplication and post-application of special paper and educational booklet) equals 0.000, this are Less than 5\%, therefore we 
reject the null hypothesis of this laboratory and we can say that it is significant. And we can say with $95 \%$ certainty that there is a moral and fundamental difference between the values of the survey before and after the provision of the special paper and the educational booklet in reducing the difficulties, which students faced while putting the pattern on paper.

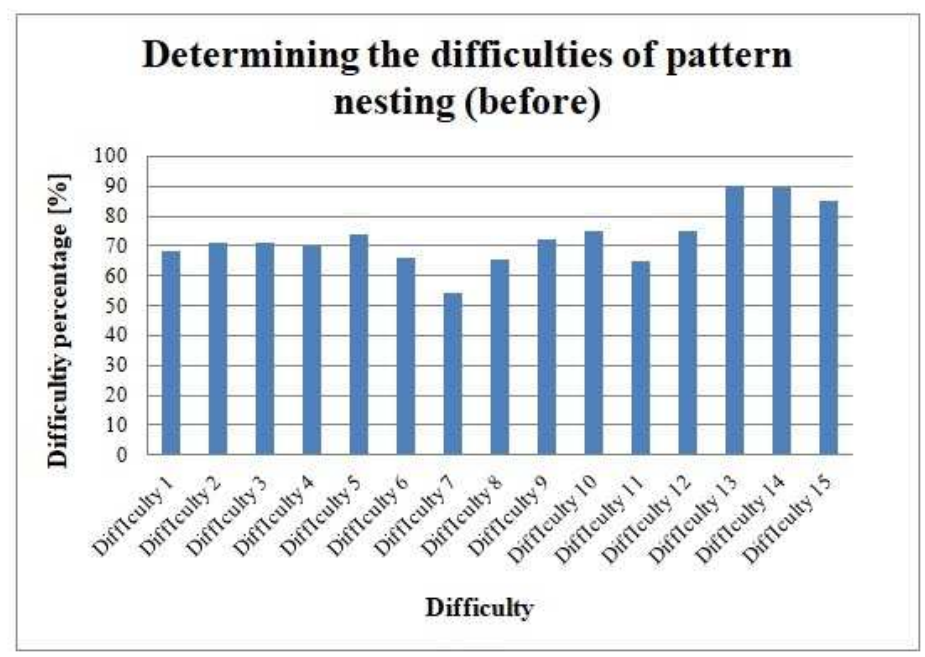

Figure 6: Determining the Difficulties Happened during Pattern Nesting.

Results in figure 6 show that the average of occurrences of the difficulties is $72.78 \%$. The less difficulty in the opinion of student is to nest the pattern parts by numbering, while the largest difficulty is to use the traditional paper.

Thus, the first hypothesis (There are difficulties facing the students of the fashion design in placing the parts of the pattern on paper (alternative to the cloth) is achieved.

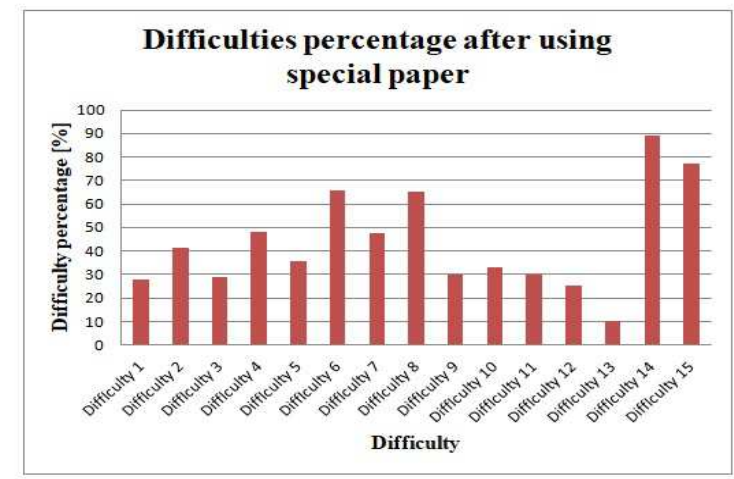

(a). After using Special Paper

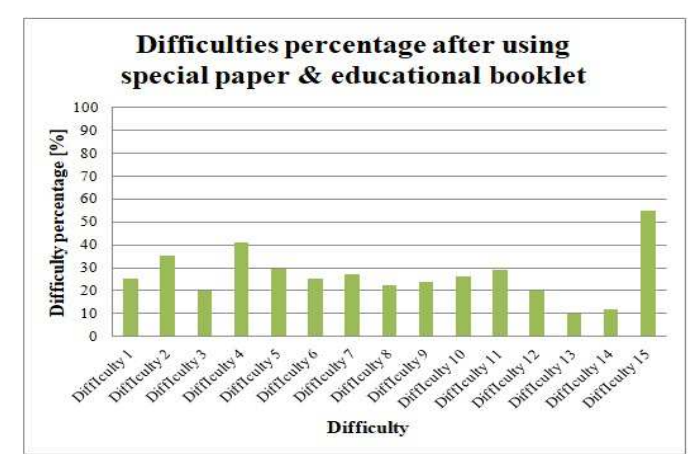

(b). After using Special Paper and Educational Booklet

Figure 7: Determining the Difficulties Happened during Pattern Nesting.

Results in figure 7 present the changes happened in the difficulties according to the solutions which are taken by the researcher to reduce the difficulties. After using the special suggested paper, the problem of traditional paper is solved and the difficulties percentage became in average (43.67\%), thus the second hypothesis (Development of a paper in a special design will make it easier for students to put the parts of the pattern on paper) is achieved. After using the special paper and educational booklet together most of difficulties are solved. They had been reduced to $26.756 \%$ in comparison to the ratio before using the solutions, thus, the third hypothesis (Existence of an educational booklet will make it easier for students to put the parts of the pattern on paper) and fourth hypothesis (There are no references and scientific books specialized in this field) are achieved. 


\section{Difficulties percentage before and after application of special paper \& educational booklet}

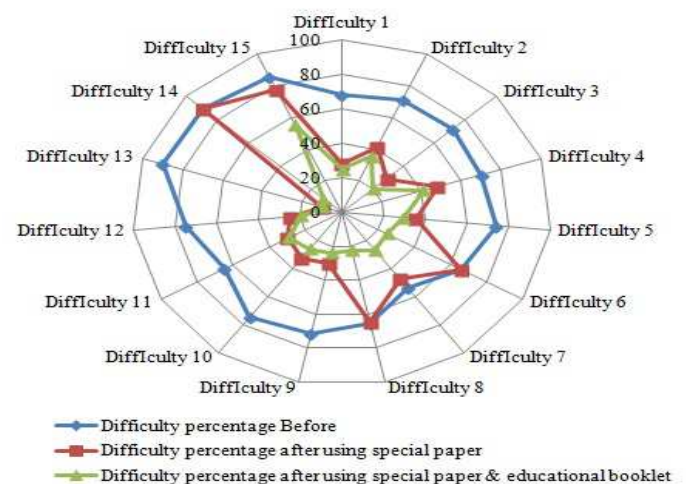

Figure 8: Comparison between Difficulties Percentages before and after Application of Solutions.

The radar chart in figure 8 concludes the influence of using the special paper and the educational booklet on reducing the difficulties percentages in comparison to the traditional paper and way in pattern nesting.

\section{CONCLUSIONS}

The process of pattern nesting can be done directly on the cloth as in the garment factories or on paper as an alternative to cloth for students and beginners. It is observed that a lot of students have difficulties to put the pattern parts correctly on paper; they do not know how to choose the suitable size of the paper width, the right way to bend the paper, how to avoid to waste areas. The aims of this research are to conclude the difficulties, which they face and suggest solutions for them. The questionnaire included 15 questions was designed and submitted to the students to analyze their use of the traditional method and normal paper in the pattern nesting, then was submitted again after using of the special paper designed with guiding lines and then it was submitted back to them after using the educational booklet and the suggested paper to determine the success of the proposed solutions in reducing the difficulties they faced.

Results indicated that the average of occurrences of the difficulties is $72.78 \%$. After using the special suggested paper, the problem of traditional paper is solved and the difficulties percentage became in average $43.67 \%$. The use of designed educational booklet with the suggested special paper, difficulties percentage had been reduced to $26.756 \%$ in comparison to the ratio before using the solutions. The importance of results of this research is to reduce the waste of paper (alternative to cloth), therefore, achieving the best pattern nesting coefficient, which lead to increase the economic aspect in the clothing industry.

\section{REFERENCES}

1. Gabr, Bahira. and Seif, Manal (2016) : "Clothing production engineering”, Al-fekr Al-arabi Press, First edition, Cairo, Egypt.

2. Bukhari, Sanaa (2007): "Basic pattern and functional and decorative darts design", Al Zahra Press, Riyadh, Kingdom of Saudi Arabia.

3. Salman, Abdul Latif (2006): "Paper; origin and development throughout history", Damascus Journal of Engineering Sciences, Issue 2, volume 22.

4. Al-Sharif, Hanadi Mohammed (2008): "Studying the functionality of military navy fabrics in Saudi Arabia", M. Sc. thesis, 
Department of Clothing and Textile, Faculty of Education for Home Economics, Mecca, Um al-Qura University.

5. Senthilkumar, B., \& Thavaraj, H. S. (2014). An evaluation of TPM implementation in clothing industry in India-a lean philosophy based approach. International Journal of Industrial Engineering \& Technology (IJIET), 4(6), 11-18.

6. Abdeen, Aliah (1986): "Studies in Women and Fashion", First Edition, Al-Bayan al-Arabi Press.

7. Abdeen, Aliah and Al-Dabagh, Zainab (2003): "Studies in textiles and the foundations of the implementation of clothing", first edition, Al-fekr Al-arabi Press, First edition, Cairo, Egypt.

8. Madi, Magda (2005): "Sewing Tools and Machines" First Edition, Al Amal Press, Alexandria, Egypt.

9. Habib, Huda (2005): "Study the properties of sports fabrics and their functional suitability for primary students", Ph. D., Department of Clothing and Textile, Faculty of Education for Home Economics, Mecca, Um Al-Qura University.

10. Areo, M. O. Regbe-Regbe: Multidimensional Impact of Cloth and Colour in Ojude-Oba Festival.

11. Hamdan, Najlaa (2007): Study of the factors affecting the garment industry and their handicaps in Saudi Arabia M. Sc thesis, Design College, Mecca, Um Al-Qura University.

12. https://en.wikipedia.org/wiki/Seam_allowance

13. http://howtosew.com/blog/q/what-seam-allowance

14. https://ar.wikipedia.org

\section{AUTHOR PROFILE}

Dr Samar Moglan had a Bachelor Degree in Home Economics, Faculty of Education for Home Economics, Umm Al-Qura University, 1999. She studied for the Master Degree in Pattern Design and Clothing Manufacture, Umm Al-Qura University, 2006. In 2011 she studied for the Ph.D. degree in Pattern Design and Clothing Making, Umm Al-Qura University. All her Publications are in the field of Pattern making. She has published many researches, such as " Design of Basic Pattern for Traditional Clothing in the Kingdom of Saudi Arabia, Scientific Conference for Home Economics, Egypt, 2008", "The Traditional Clothing in the Kingdom of Saudi Arabia, The Kingdom of Saudi Arabia, King Fahd National Index, 2009.", "Design and Implement Ready-To-Wear Clothes that are Functional and Aesthetic Suitable for the People with Special Needs, The First International Conference for Home Economics, Cairo, 2011.", "Design and Implement Ready-To-Wear Clothes That are Functional and Aesthetic Suitable for the People with Special Needs, First Book for Publishing \&amp; Distribution Cairo, 2014.”, "Design and Implementation of Lab Coat for Workers with Special Needs, Egyptian Journal of Home Economics, Helwan University, 2017.”, "Designing of an Educational Book for Drawing the Basic Flat Pattern, International Journal of General Engineering and Technology (IJGET), 2017.”, “Training Program for the Steps of Taking Body Measurements Using an Innovative Device, Journal of Arts, Literature, Humanities and Sociology, Emirates College, 2019." Recently she published an article with the title of "Determination of the best way for putting the pattern parts correctly on the paper (Similar to Cloth) (Pattern Nesting), International Journal Of Textile And Fashion Technology (IJTFT), 2019." She is a member in many scientific associations, such like: The Association of Disabled Children, Mecca- KSA. And also in The Egyptian Association of Home Economics, Cairo - ARE. She has much participation, like: Participation in the Activities of the Fourth Annual International Scientific Conference at the Faculty of Specific Education. Tanta University, April 2017, in the event of preparation the students to the Tenth Scientific Meeting, Umm Al-Qura University, 2018, in the Event of Mecca Promise and Rank, 2018 and in organizing Exhibitions of the Subjects in the College of Designs. 
